\title{
VARIABILITY OF THE HUMAN PLACENTAL SHAPES IN NORMAL AND PRE-ECLAMPTIC PREGNANCIES AND ITS EFFECTS ON PLACENTAL AND FOETAL OUTCOMES
}

\author{
Ankit Jain1, Rashmi Jain², Sonia Baweja3 ${ }^{3}$ Sandeep Marskole, Monika Gupta ${ }^{5}$ \\ ${ }_{1}^{1}$ Resident, Department of Anatomy, Gandhi Medical College, Bhopal, Madhya Pradesh. \\ ${ }^{2}$ Resident, Department of Pathology, Gandhi Medical College, Bhopal, Madhya Pradesh. \\ ${ }^{3}$ Associate Professor, Department of Anatomy, Gandhi Medical College, Bhopal, Madhya Pradesh. \\ ${ }^{4}$ Assistant Professor, Department of Anatomy, Gandhi Medical College, Bhopal, Madhya Pradesh. \\ 5Demonstrator, Department of Anatomy, Gandhi Medical College, Bhopal, Madhya Pradesh.
}

ABSTRACT
BACKGROUND
A fetus is dependent on the placenta for growth and development. Pregnancies complicated by metabolic diseases like
hypertension and diabetes are accompanied by gross pathological changes in the placenta. Hypertensive pregnancies affect the
maternal health as well as architecture and functions of the placenta.

AIMS

To assess the variation in the shapes of the placenta in pre-eclamptic and normal pregnancies and the effects of these variable placental shapes on placental weight and foetal weight.

\section{MATERIALS AND METHODS}

Eighty placentae were divided into forty each of normotensive and pre-eclamptic pregnancies were studied. After delivery, the weight of the baby was noted. The shape of the placenta was observed visually and weight of the placenta was taken by using the standard weighing machine.

\section{RESULTS}

In this study $62.5 \%$ placentae were discoidal shaped in control group, whereas in the pre-eclamptic group 52.5\% placentae were oval shaped. The proportion of irregular shaped placentae was higher in the pre-eclamptic group. Among the non-discoidal shaped placentae, $60 \%$ placentae were associated with lower placental weight and lower birth weight. We found a significant relationship between placental shape and foetal birth weight.

\section{CONCLUSION}

The placentae from hypertensive mothers significantly differ from the normal pregnancies, which may be associated with altered placental functions and ultimately foetal outcome. Thus assessment of abnormally shaped placentae at the earliest stage by sonography might be helpful in early identification of fetus at risk and better management of such pregnancies.

\section{KEYWORDS}

Foetal Weight, Placental Shape, Placenta, Pre-eclampsia.

HOW TO CITE THIS ARTICLE: Jain A, Jain R, Baweja S, et al. Variability of the human placental shapes in normal and pre-eclamptic pregnancies and its effects on placental and foetal outcomes. J. Evolution Med. Dent. Sci. 2016;5(80):5929-5932, DOI: 10.14260/Jemds/2016/1339

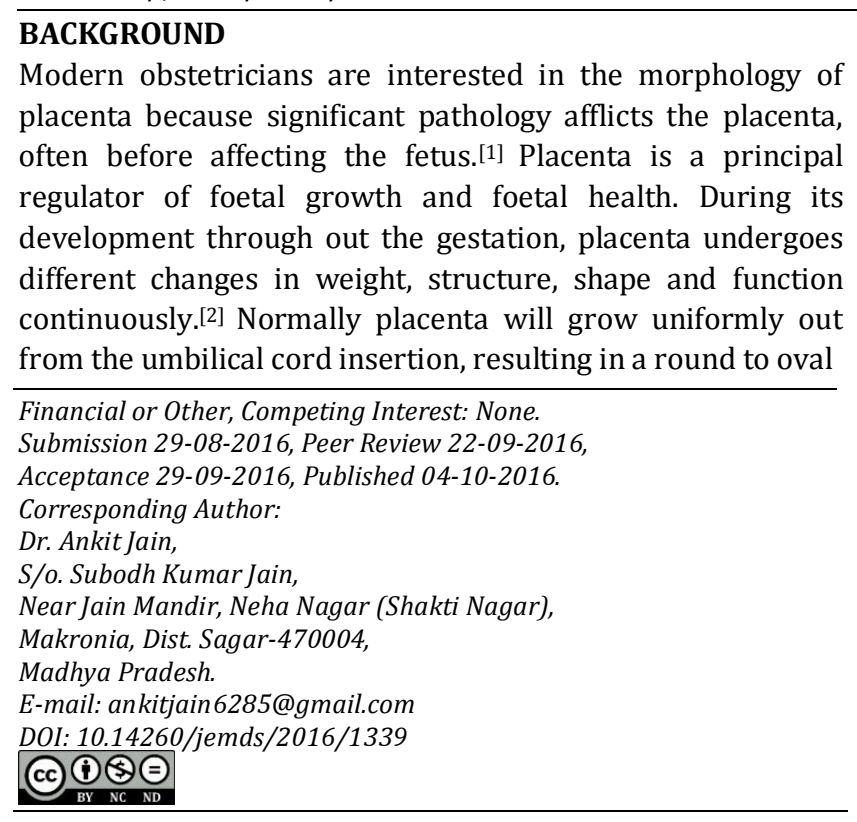

shape of placenta.[3] In clinical practice, the shape of the placenta varies from round to oval, bilobate to multilobate or could be considered as irregular. The shape of the placenta is thought to be influenced by the regional variations in the decidua, changes in maternal vascular supply and probably the site of its original implantation in the uterus. ${ }^{[4]}$ Abnormalities of the shape of placenta like placenta succenturiata, fenestrated placenta, circumvallate and circummarginate placenta have been encountered accidently. These abnormal shapes of the placentae are associated with reduced placental efficiency, which may lead to impaired placental and potentially foetal development.[5]

Pre-eclampsia is one of the common complications during pregnancy. It has been recorded that maternal uteroplacental blood flow is decreased in pre-eclampsia, because there is maternal vasospasm.[6] This results in histomorphological changes in ischaemic placentae, which leads to foetal hypoxia. Intrauterine growth retardation, premature delivery and foetal death occur as a consequence of foetal hypoxia.[7] Hence, proper examination of the placentae in utero as well as 
postpartum gives valuable information about the state of foetal wellbeing.

The objective of this study is to compare the changes in the shape of placentae in normal and pre-eclamptic pregnancies and to assess the effects of variable placental shape on placental weight and foetal weight.

\section{MATERIALS AND METHODS}

It was an observational comparative study conducted in the Department of Anatomy and Department of Obstetrics and Gynaecology, Gandhi Medical College and associated Sultania Zanana Hospital, Bhopal (MP), during January 2015 to December 2015. A total of 80 placentae were collected from pregnant women delivered in Sultania Zanana Hospital, after permission from Institutional Ethics Committee. All mothers were properly explained about the study, and their informed consent was obtained.

Pre-eclampsia was diagnosed when women had proteinuria with systolic $\mathrm{BP} \geq 140 \mathrm{mmHg}$ and diastolic $\mathrm{BP} \geq 90$ mmHg measured on two or more occasions at least $4 \mathrm{hrs}$ apart after the 20th week of gestation. The presence of proteinuria was conformed when there was a urine dipstick value of $1+$ (>30 mg/dL) on two different occasions at least 6 hours apart.[8] On this basis, subjects were divided into two groups. Group I consist of placentae obtained from normal pregnant women $(n=40)$ with gestational age $37-40$ weeks. Group II consist of placentae obtained from pre-eclamptic women $(n=40)$ of similar gestational age. Pregnancies associated with essential hypertension, gestational diabetes, anaemia, multiple pregnancies and hepatorenal disorders were excluded from this study.

In this study, mothers and their neonates were identified by given code numbers. After delivery, placentae were collected and washed in the running tap water to clean all blood. Birth weight of the foetus and placental weight was recorded by using standard weighing machine. The shape of the placenta was noted visually and variations in the shape the placentae were recognised. Discoidal and oval shaped placentae were considered as normal shaped placentae [Fig. $1 \mathrm{~A}, \mathrm{~B}]$, whereas triangular and irregular shaped placentae were considered as abnormal shaped placentae [Fig. 2A, B].

Statistical analysis of data was performed by using Statistical Package for Social Sciences (SPSS) version 15.0 (Chicago, IL). The statistical significance was analysed by using Chi-square test for categorical data. The significance of differences between group parameters were considered significant if $\mathrm{p}<0.05$.

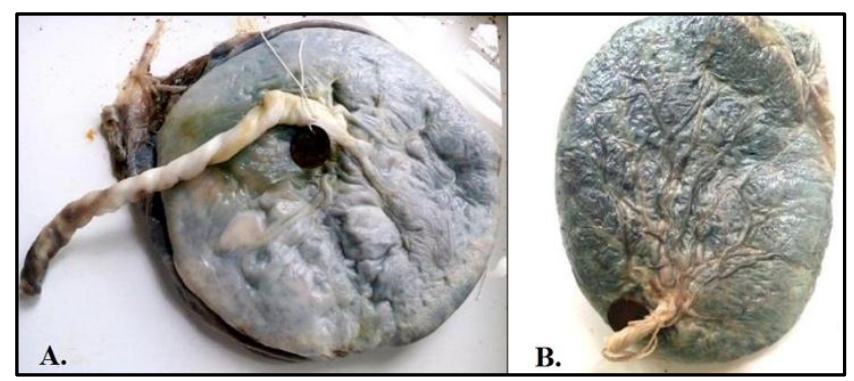

Fig. 1: A. Discoidal Shaped Placenta, B. Oval Shaped Placenta

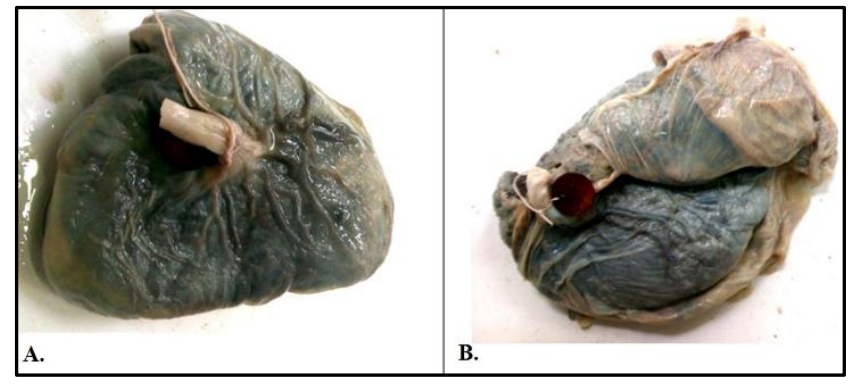

Fig. 2: A. Triangular Shaped Placenta, B. Irregular Shaped Placenta

\begin{tabular}{|c|c|c|}
\hline $\begin{array}{l}\text { Shape of } \\
\text { Placenta }\end{array}$ & $\begin{array}{l}\text { Control Group } \\
(n=40)\end{array}$ & $\begin{array}{l}\text { Pre-Eclamptic } \\
\text { Group }(n=40)\end{array}$ \\
\hline Discoidal & 25 (62.5\%) & $12(30 \%)$ \\
\hline Oval & $12(30 \%)$ & $21(52.5 \%)$ \\
\hline $\begin{array}{l}\text { Abnormal } \\
\text { Shape* }\end{array}$ & $3(7.5 \%)$ & 7 (17.5\%) \\
\hline Total & $40(100 \%)$ & $40(100 \%)$ \\
\hline \multicolumn{3}{|c|}{$\begin{array}{c}\text { Table 1: Distribution of Placental Shape in Normal and } \\
\text { Pre-Eclamptic Pregnancies }\end{array}$} \\
\hline
\end{tabular}

Chi-square $\left(\chi^{2}\right)=8.622, \mathrm{df}=2, \mathrm{p}=0.013$. Statistically highly significant. *Abnormal shapes included triangular and irregular shaped placentae.

\begin{tabular}{|c|c|c|c|c|}
\hline \multirow{2}{*}{$\begin{array}{c}\text { Shape of } \\
\text { Placenta }\end{array}$} & \multicolumn{3}{|c|}{$\begin{array}{c}\text { Placental Weight } \\
\text { (In Grams) }\end{array}$} & \multicolumn{2}{c|}{ Total } \\
\cline { 2 - 5 } & $\mathbf{4 0 0}$ & $\mathbf{4 0 1 - 5 0 0}$ & $>\mathbf{5 0 0}$ & \\
\hline Discoidal & $\begin{array}{c}8 \\
(21.62 \%)\end{array}$ & $\begin{array}{c}22 \\
(59.46 \%)\end{array}$ & $\begin{array}{c}7 \\
(18.92 \%)\end{array}$ & $\begin{array}{c}37 \\
(100 \%)\end{array}$ \\
\hline Oval & $\begin{array}{c}12 \\
(36.36 \%)\end{array}$ & $\begin{array}{c}16 \\
(48.48 \%)\end{array}$ & $\begin{array}{c}5 \\
(15.16 \%)\end{array}$ & $\begin{array}{c}33 \\
(100 \%)\end{array}$ \\
\hline $\begin{array}{c}\text { Abnormal } \\
\text { Shape* }\end{array}$ & $6(60 \%)$ & $3(30 \%)$ & $1(10 \%)$ & $\begin{array}{c}10 \\
(100 \%)\end{array}$ \\
\hline
\end{tabular}

Table 2: Relation between Placental Shape and Placental Weight

Chi-square $\left(\chi^{2}\right)=5.66, \mathrm{df}=4, \mathrm{p}=0.225$, Statistically not significant. *Abnormal shapes included triangular and irregular shaped placentae.

\begin{tabular}{|c|c|c|c|}
\hline $\begin{array}{c}\text { Shape of } \\
\text { Placenta }\end{array}$ & $\begin{array}{c}\text { Foetal Birth Weight } \\
\text { (In Grams) }\end{array}$ & \multirow{2}{*}{ Total } \\
\cline { 2 - 3 } & $<\mathbf{2 5 0 0}$ & $\mathbf{2 5 0 0}$ & \\
\hline Discoidal & $8(21.62 \%)$ & $\begin{array}{c}29 \\
(78.38 \%)\end{array}$ & $\begin{array}{c}37 \\
(100 \%)\end{array}$ \\
\hline Oval & $\begin{array}{c}14 \\
19\end{array}$ & $\begin{array}{c}33 \\
(100 \%)\end{array}$ \\
\hline Altered Shape* & $6(60 \%)$ & $4(40 \%)$ & $\begin{array}{c}10 \\
(100 \%)\end{array}$ \\
\hline \multicolumn{3}{|c|}{ Table 3: Relation between Placental Shape and Foetal } \\
\hline \multicolumn{3}{|c|}{ Birth Weight } \\
\hline
\end{tabular}

Chi-square $\left(\chi^{2}\right)=6.458, \mathrm{df}=2, \mathrm{p}=0.039$, Statistically significant. *Abnormal shapes included triangular and irregular shaped placentae.

\section{DISCUSSION}

The full-term placenta is round or discoidal shaped with the umbilical cord inserted into the center. $[9,10,11]$ In the present study, the shape of the placenta was found to be discoidal in $62.5 \%$ cases and oval in 30\% cases of the control group, whereas in pre-eclamptic group oval shaped placentae were found in $52.5 \%$ cases and discoidal shaped placentae were 
found in $30 \%$ cases [Table 1]. These findings suggested that discoidal and oval-shaped placentae were common in both groups.

Placenta acts as a functional unit between mother and the foetus. Therefore, any pathology related to the mother or foetus will influence the normal function and histomorphology of the placenta.[12] Various altered placental shapes like heart shaped, spindle-shaped, ring-shaped and pear-shaped placentae were reported without any clinical significance. ${ }^{[13]} \mathrm{A}$ variable uteroplacental environment affects macroscopic placental structure as a change in shape. The microscopic growth of the human placenta involves repeated branching of the vascular trees. Variable shapes of placentae were derived by changing in the arborisation of the vascular tree.[3] This is supported by Cotter et al, who reported disruption of the normal field of spiral arteries significantly alters placental shapes resulting in a greater frequency of irregular and bipartite shaped placentae. Thus, a placental shape reflects the underlying maternal vascular bed.[14]

Sudha et al observed various altered shaped placentae in pregnancies complicated by anaemia, gestational diabetes mellitus and pre-eclampsia. These altered shapes may be due to the underlying pathology in these diseases.[15] This is supported by Yampolsky $\mathrm{M}$ et al, who reported abnormal shaped placentae were quite regular and their regularity suggests that there may be a common underlying pathological mechanism responsible for such variability of observed shapes of placentae.[3]

In this study apart from the discoidal and oval-shaped placentae, we also found one triangular shaped and two irregular shaped placentae in the control group, whereas in pre-eclamptic group 7 (17.5\%) placentae were irregular shaped. The proportion of irregular shaped placentae was higher in pre-eclamptic group as compared to the control group [Table 1]. Complicated diseases are metabolic in nature and they affect the placental efficiency and function. Apart from the pre-existing vasospasm in hypertension, apoptosis and compensatory hyperplasia of the parenchyma run side by side. These changes influence the shapes of placentae, which deviate from the normal.[16] This is supported by Egbor $\mathrm{M}$ et al, who reported abnormal placental morphology in preeclamptic toxaemias.[17]

Pregnant women who experienced pre-eclampsia had reduced placental weight and more oval shaped placentae.[18] In the present study, we also found that oval shaped placentae were more $(52.5 \%)$ in pre-eclamptic group as compared to control group [Table 1]. Barker et al observed that reduced placental weight and surface area was associated with risk of developing hypertension in adult life.[19] In this study, we observed that most of the abnormal shaped placentae were associated with lower placental weight [Table 2].

In the present study, we observed a significant relationship between placental shape and foetal birth weight. Most of the abnormal shaped placentae were associated with the low birth weight [Table 3]. Abnormal placental shapes were associated with an altered placental vascular architecture, which in turn was associated with a reduced placental efficiency. Therefore, abnormal placental shapes act as a marker for maternal uteroplacental and fetoplacental vascular pathology that impacts negatively on the placenta and potential foetal development.[20] This is supported by Yampolsky $\mathrm{M}$ et al,[3] who found that an irregular chorionic plate shape has been associated with lower birth weight to placental weight ratio.

\section{CONCLUSION}

The adverse effects of hypertension on the outcome of pregnancy are well established. The present study highlights the variation in the shapes of placenta between normal healthy and pre-eclamptic mothers. Abnormal shapes of placentae were found more in pre-eclamptic pregnancies, which weighted significantly less than the average weight of normal placentae. Abnormal shaped placentae were also associated with low birth weight. These results suggested that pregnancies complicated by hypertension affect the architecture and functions of the placenta, which ultimately leads to the adverse perinatal outcome. Thus assessment of abnormally shaped placentae at the earliest stage by sonography might be helpful in early identification of fetus at risk. Proper management of such pregnancies at the earliest stage reduces the perinatal morbidity and mortality.

\section{REFERENCES}

1. Goyal M, Singh KN, Agarwal R, et al. Correlation of prenatal ultrasound findings with placental pathology in high risk pregnancies. Journal of Evolution of Medical and Dental Sciences 2014:3(3):665-72.

2. Teasdale F. Gestational changes in the functional structure of the human placenta in relation to foetal growth: a morphometric study. American Journal of Obstetrics and Gynecology 1980;137(5):560-8.

3. Yampolsky M, Salafia CM, Shlakhter O, et al. Modeling the variability of shapes of a human placenta. Placenta 2008;29(9):790-7.

4. Benirschke K, Kaufmann P, Baergen R. Pathology of the human placenta. $5^{\text {th }}$ edn. New York: Springer Verlag 2006:121-59.

5. Cunningham FG, Leveno KJ, Bloom SL, et al. William's obstetrics. 22nd edn. Newyork: McGraw -Hill 2005:828-29.

6. Aardema MW, Oosterhof H, Timmer A, et al. Uterine artery doppler flow and uteroplacental vascular pathology in normal pregnancies and pregnancies complicated by preeclampsia and small for gestational age fetuses. Placenta 2001;22(5):405-11.

7. Zhou Y, Damsky CH, Fisher SJ. Preeclampsia is associated with failure of human cytotrophoblasts to mimic a vascular adhesion phenotype. One cause of defective endovascular invasion in this syndrome? The Journal of Clinical Investigation 1997;99(9):2152-64.

8. Park K. Park's textbook of preventive and social medicine. $22^{\text {nd }}$ edn. Jabalpur, India: M/S Banarsidas Bhanot 2013.

9. Kulandaivelu AR, Srinivasamurthy BC, Murugan A, et al. Morphology and morphometric study of human placenta in rural southern India. British Journal of Medicine \& Medical Research 2014;4(15):2995-3008.

10. Raghunath G, Vijayalakshmi VS. A study on the morphology and the morphometry of the human placenta and its clinical relevance in a population in Tamilnadu. Journal of Clinical and Diagnostic Research 2011;5(2):282-86.

11. Hamilton WJ, Boyd JD. Observation on the human placenta. Proc R Soc Med 1951;44(6):489-96.

12. Hargitai B, Marton T, Cox BM. Examination of human placenta. J Clin Pathol 2004;57(8):785-92. 
13. Arey LB. Developmental anatomy: a textbook and laboratory manual of embryology. $7^{\text {th }}$ edn. Philadelphia: WB Saunders 1974:131-6.

14. Cotter SL, Klika V, Kimpton L, et al. A stochastic model for early placental development. Journal of the Royal Society 2014;11(97):20140149.

15. Sudha R, Sivakumar V, Christilda FJ. Study of shape of placenta and its relation to placental weight in normal and complicated pregnancies. National Journal of Basic Medical Sciences 2012;2(4):307-11.

16. Queenan JT. Management of high risk pregnancy. $4^{\text {th }}$ edn. England: Blackwell science 1999:261-70.
17. Egbor M, Ansari T, Morris N, et al. Pre-eclampsia and foetal growth restriction: how morphometrically different is the placenta? Placenta 2006;27(6-7):727-34.

18. Kajantie E, Thornburg KL, Eriksson JG, et al. In preeclampsia, the placenta grows slowly along its minor axis. International Journal of Developmental Biology 2009;54(2-3):469-73.

19. Barker DJ, Thornburg KL, Osmond C, et al. The surface area of the placenta and hypertension in the offspring in later life. The International Journal of Developmental Biology 2010;54(2-3):525-30.

20. Salafia CM, Yampolsky M, Misra DP, et al. Placental surface shape, function, and effects of maternal and foetal vascular pathology. Placenta 2010;31(11):958-62. 